This information is current as of April 25, 2023. 


\title{
MRI Texture Analysis Reveals Bulbar Abnormalities in Friedreich Ataxia
}

\author{
T.A. Santos, C.E.B. Maistro, C.B. Silva, M.S. Oliveira, M.C. França, Jr, and G. Castellano
}

O-

\begin{abstract}
BACKGROUND AND PURPOSE: Texture analysis is an image processing technique that can be used to extract parameters able to describe meaningful features of an image or ROI. Texture analysis based on the gray level co-occurrence matrix gives a second-order statistical description of the image or ROI. In this work, the co-occurrence matrix texture approach was used to extract information from brain MR images of patients with Friedreich ataxia and a control group, to see whether texture parameters were different between these groups. A longitudinal analysis was also performed.
\end{abstract}

MATERIALS AND METHODS: Twenty patients and 21 healthy controls participated in the study. Both groups had 2 sets of T1-weighted MR images obtained 1 year apart for every subject. ROIs chosen for analysis were the medulla oblongata and pons. Texture parameters were obtained for these ROls for every subject, for the 2 sets of images. These parameters were compared longitudinally within groups and transversally between groups.

RESULTS: The comparison between patients and the control group showed a significant differences for the medulla oblongata ( $t$ test, $P<.05$, Bonferroni-corrected) but did not show a statistically significant difference for the pons. Longitudinal comparison of images obtained 1 year apart did not show differences for either patients or for controls, in any of the analyzed structures.

CONCLUSIONS: Gray level co-occurrence matrix-based texture analysis showed statistically significant differences for the medulla oblongata of patients with Friedreich ataxia compared with controls. These results highlight the medulla as an important site of damage in Friedreich ataxia.

ABBREVIATIONS: $\mathrm{Cl}=$ the first control acquisition; $\mathrm{C2}=$ the second control acquisition; $\mathrm{FA}=$ Friedreich ataxia; $\mathrm{GLCM}=$ gray level co-occurrence matrix; $\mathrm{P} 1=$ the first patient acquisition; $\mathrm{P} 2$ = the second patient acquisition

D gital images have revolutionized medicine because in addition to the readily available visual information provided by their analog counterparts, they can be mathematically manipulated by myriad processing techniques that allow extraction of many other types of information. In particular, the human eye can

Received January 30, 2015; accepted after revision May 18.

From the Neurophysics Group (T.A.S., C.E.B.M., M.S.O., G.C.), Gleb Wataghin Physics Institute, and Department of Neurology (C.B.S., M.C.F.), Medical Sciences School, University of Campinas, Brazil; and Brazilian Institute of Neuroscience and Neurotechnology (BRAINN) (São Paulo Research Foundation) (T.A.S., C.E.B.M., C.B.S., M.S.O., M.C.F., G.C.), Campinas, São Paulo, Brazil.

This work was supported by São Paulo Research Foundation (Brazil), grants 2012/ 24363-2, 2013/01766-7, 2013/07559-3, 2013/16273-6.

Please address correspondence to Gabriela Castellano, PhD, University of Campinas/ IFGW, Rua Sergio Buarque de Holanda, 777, Cidade Universitária “Zeferino Vaz," 13083-859-Campinas-São Paulo, Brazil; e-mail: gabriela@ifi.unicamp.br

- Indicates open access to non-subscribers at www.ajnr.org

\# Indicates article with supplemental on-line table.

Evidence-Based Medicine Level 2.

http://dx.doi.org/10.3174/ajnr.A4455 only distinguish around 60 shades of gray for a given adjustment of the pupil, whereas digital medical images such as those provided by MR imaging or x-ray CT normally use around 4000 gray levels for data encoding. Texture analysis ${ }^{1}$ is the name given to a set of image-processing approaches that may be used for an efficient image classification based on a reduced parameter set or to detect subtle alterations in the gray level distribution of an image or ROI. Texture analysis approaches have been widely applied in medicine to differentiate normal and pathologic tissue, such as in epilepsy, ${ }^{2-4}$ Machado-Joseph disease, ${ }^{5}$ and central nervous system tumors. ${ }^{6-8}$ In particular, texture analysis based on the gray level co-occurrence matrix (GLCM) gives a second-order statistical description of the image or ROI. ${ }^{9,10}$ In this work, the GLCM approach was used to extract information from brain MR images of patients with Friedreich ataxia (FA) and a control group. We were primarily interested in looking for differences between these groups, but we also investigated whether texture parameters correlated with clinical data in the FA group.

FA is the most common autosomal recessive ataxia, and it is 
characterized by early onset and slowly progressive gait ataxia, dysmetria, dysarthria, and deep sensory abnormalities. ${ }^{11}$ It is caused by homozygous triplet GAA expansions in the first intron of the FXN gene on chromosome 9q13 in 96\% of patients. ${ }^{12,13}$ This leads to dramatic underexpression of the encoded protein frataxin, which is essential for proper neuronal mitochondrial functioning. ${ }^{11}$ The net results of the mutation are marked and progressive neuronal loss in the dorsal root ganglia, pyramidal tracts, and dentate nuclei of the cerebellum. ${ }^{14}$

Brain MR imaging of patients with FA does not present clearly visible changes. However, some previous studies have already shown alterations by using advanced techniques. Indeed, previous voxel-based morphometry studies showed gray matter and white matter atrophy in portions of the cerebellum and brain stem in FA. ${ }^{15-18}$ The spinal cord area was found to be reduced in these patients. ${ }^{19}$ Also, patients with FA have WM damage in the brain stem, cerebellum, and cerebellar peduncles. ${ }^{16,17,20-22}$ To the best of our knowledge, there is no previous study on GLCM texture analysis of MR imaging in FA. We believe such a study would be important because texture analysis is a powerful tool able to identify subtle abnormalities before true atrophy appears. ${ }^{2,3}$ It has proved useful in finding damaged areas in closely related conditions, such as Machado-Joseph disease. ${ }^{5}$ In addition, it is highly reproducible and provides quantitative results. Taken together, these characteristics make texture analysis a technique appropriate for longitudinal MR imaging-based studies, which are extremely rare in FA. In this scenario, we recruited a representative cohort of patients who underwent 2 MR imaging scans 1 year apart and performed transversal and longitudinal texture analyses. We focused the analyses on brain stem structures, the pons and medulla oblongata, because these play a key role in the pathogenesis of the disease.

\section{MATERIALS AND METHODS}

Twenty patients with FA (mean age, $27.6 \pm 9.6$ years; 14 women) and a control group of 21 healthy subjects (mean age, $28.6 \pm 5.3$ years; 12 women) participated in this study. All patients had molecular confirmation of FA and were followed at the Neurogenetics Clinic at the University of Campinas. Mean ages at diagnosis and disease duration were $15.4 \pm 5.2$ and $13.1 \pm 8.4$ years, respectively. We used the Friedreich ataxia rating scale at each visit to quantify disease severity for each patient. ${ }^{23}$ The study was approved by the local ethics committee, and all participants signed an informed consent form, before data acquisition.

MR imaging data were acquired in a $3 \mathrm{~T}$ Achieva scanner (Philips Healthcare, Best, the Netherlands) at the Clinics Hospital of our university. Images used for texture analysis were T1weighted, acquired with an 8-channel head coil, with an FOV of $240 \times 240 \times 180 \mathrm{~mm}^{3}$, voxel size of $1 \times 1 \times 1 \mathrm{~mm}^{3}$, TR of $7 \mathrm{~ms}$, and TE of $3.2 \mathrm{~ms}$.

Given an ROI in an image and a pixel distance in a given direction (eg, 2 pixels in the vertical direction), the GLCM approach consists of calculating, for every possible pair of gray levels, how many times they co-occur in the ROI in this direction and distance. From a GLCM, statistical parameters can then be computed, the most usual ones being the following ${ }^{24}$ : contrast, homogeneity, correlation, variance, sum average, sum variance, differ-

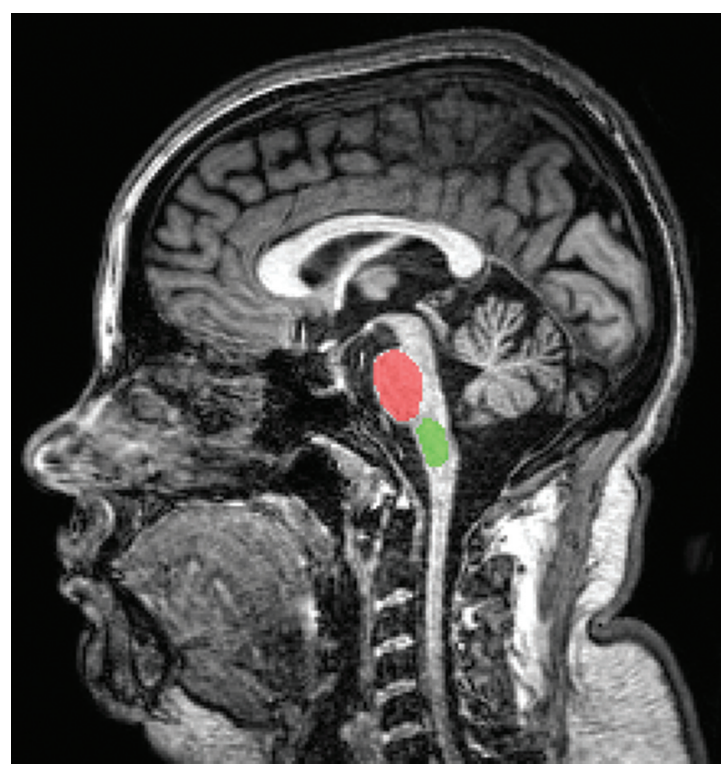

FIG 1. Example of segmented ROls in the center section of the MR imaging examination for a patient with FA. The region in red indicates the pons, and the region in green indicates the medulla oblongata.

ence variance, uniformity, entropy, sum entropy, and difference entropy. Formulas and descriptions for these parameters can be found in the On-line Table.

As mentioned, the ROIs investigated in this work were the medulla oblongata and the pons, known to be affected by FA. These structures were manually segmented, by using MaZda software (http://www.eletel.p.lodz.pl/programy/mazda/), ${ }^{25}$ in 7 sagittal sections for each subject (consisting of the central section plus 3 anterior and 3 posterior sections). Figure 1 shows an example of these ROIs, segmented in 1 section, for a patient with FA, where the region in red is the pons and the region in green is the medulla oblongata. GLCMs were computed for every section, also by using the MaZda software. This software computes GLCMs for 4 directions (horizontal, vertical, and 2 diagonals) and 5 distances (1-5 pixels), giving 20 GLCMs per section or, in the present case, 140 GLCMs per ROI (280 per subject). Because the aforementioned 11 parameters were computed for every GLCM, the total number of parameters was 1540 per ROI (3080 per subject).

To reduce the number of parameters, we computed 2 averages. First, an average over the 7 ROI sections was calculated for each parameter, weighted by the segmented area in each section; this procedure had the effect of "merging" the information obtained for a given ROI that was previously "sliced." Second, an average over the 4 directions was calculated for each parameter. The idea behind this approach was to make the parameters direction-independent, because even if a given tissue had a preferred structural direction, the position axes of the acquired MR images might be slightly different for different subjects; this difference could affect the results. After these procedures, parameters were reduced to 55 per ROI (110 per subject).

Finally, GLCM texture parameters were compared statistically, by using a $t$ test, Bonferroni corrected, with a significance level of $\alpha=.05$. Each GLCM parameter was analyzed longitudinally within a group, comparing images taken 1 year apart, and transversally between the groups. For the longitudinal compari- 


\begin{tabular}{|c|c|c|c|c|c|c|c|c|c|}
\hline \multirow{2}{*}{$\begin{array}{l}\text { GLCM Distance } \\
\text { (pixel) }\end{array}$} & \multirow[b]{2}{*}{ Parameter } & \multicolumn{4}{|c|}{ Group (Mean) } & \multicolumn{4}{|c|}{$\begin{array}{c}\text { Comparison ( } P \text { Value, } \\
\text { Bonferroni-Corrected, } t \text { Test) }\end{array}$} \\
\hline & & P1 & P2 & $\mathrm{Cl}$ & $\mathrm{C} 2$ & $\mathrm{Pl} \times \mathrm{Cl}$ & $\mathrm{P} 1 \times \mathrm{C} 2$ & $\mathrm{P} 2 \times \mathrm{Cl}$ & $\mathrm{P} 2 \times \mathrm{C} 2$ \\
\hline \multicolumn{10}{|l|}{ Medulla oblongata } \\
\hline 1 & Correlation & $0.27 \pm 0.03$ & $0.25 \pm 0.05$ & $0.45 \pm 0.09$ & $0.41 \pm 0.10$ & $.000^{\mathrm{b}}$ & $.000^{\mathrm{b}}$ & $.000^{\mathrm{b}}$ & $.000^{b}$ \\
\hline 1 & Variance & $11.84 \pm 3.36$ & $12.80 \pm 4.14$ & $17.71 \pm 5.10$ & $15.60 \pm 4.83$ & $.008^{\mathrm{b}}$ & .188 & .413 & 1.00 \\
\hline 1 & Sum average & $86.25 \pm 3.45$ & $86.18 \pm 2.62$ & $110.75 \pm 5.83$ & $103.48 \pm 14.32$ & $.000^{\mathrm{b}}$ & $.002^{\mathrm{b}}$ & $.000^{\mathrm{b}}$ & $.002^{\mathrm{b}}$ \\
\hline 1 & Sum variance & $32.55 \pm 9.52$ & $34.61 \pm 10.86$ & $50.24 \pm 16.52$ & $43.56 \pm 14.79$ & $.014^{\mathrm{b}}$ & .103 & .484 & 1.00 \\
\hline 1 & Entropy & $1.46 \pm 0.15$ & $1.47 \pm 0.07$ & $2.00 \pm 0.08$ & $1.86 \pm 0.23$ & $.000^{\mathrm{b}}$ & $.000^{\mathrm{b}}$ & $.000^{\mathrm{b}}$ & $.000^{\mathrm{b}}$ \\
\hline 1 & Sum entropy & $0.98 \pm 0.08$ & $0.99 \pm 0.04$ & $1.36 \pm 0.06$ & $1.25 \pm 0.17$ & $.000^{\mathrm{b}}$ & $.000^{\mathrm{b}}$ & $.000^{\mathrm{b}}$ & $.000^{\mathrm{b}}$ \\
\hline 1 & $\begin{array}{l}\text { Difference } \\
\text { entropy }\end{array}$ & $0.71 \pm 0.04$ & $0.72 \pm 0.04$ & $0.93 \pm 0.05$ & $0.86 \pm 0.11$ & $.000^{\mathrm{b}}$ & $.000^{\mathrm{b}}$ & $.000^{\mathrm{b}}$ & $.002^{\mathrm{b}}$ \\
\hline 1 & Homogeneity & $0.21 \pm 0.05$ & $0.20 \pm 0.02$ & $0.27 \pm 0.03$ & $0.27 \pm 0.04$ & $.004^{\mathrm{b}}$ & .165 & $.000^{\mathrm{b}}$ & $.000^{\mathrm{b}}$ \\
\hline 2 & Correlation & $0.05 \pm 0.05$ & $0.04 \pm 0.06$ & $0.18 \pm 0.08$ & $0.17 \pm 0.10$ & $.000^{\mathrm{b}}$ & $.001^{\mathrm{b}}$ & $.000^{\mathrm{b}}$ & $.002^{\mathrm{b}}$ \\
\hline 3 & Correlation & $0.04 \pm 0.05$ & $0.02 \pm 0.05$ & $0.13 \pm 0.07$ & $0.14 \pm 0.08$ & $.002^{\mathrm{b}}$ & $.004^{\mathrm{b}}$ & $.000^{\mathrm{b}}$ & $.000^{\mathrm{b}}$ \\
\hline 4 & Correlation & $-0.01 \pm 0.04$ & $-0.03 \pm 0.05$ & $0.08 \pm 0.07$ & $0.08 \pm 0.08$ & $.004^{\mathrm{b}}$ & $.013^{\mathrm{b}}$ & $.000^{\mathrm{b}}$ & $.001^{\mathrm{b}}$ \\
\hline 5 & Correlation & $-0.02 \pm 0.03$ & $-0.03 \pm 0.05$ & $0.06 \pm 0.07$ & $0.05 \pm 0.07$ & $.006^{\mathrm{b}}$ & .055 & $.008^{b}$ & $.049^{\mathrm{b}}$ \\
\hline \multicolumn{10}{|c|}{ 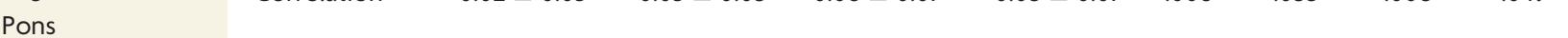 } \\
\hline 1 & $\begin{array}{l}\text { Difference } \\
\text { variance }\end{array}$ & $7.27 \pm 2.24$ & $7.56 \pm 1.89$ & $5.58 \pm 1.45$ & $5.38 \pm 1.11$ & .490 & .142 & .125 & $.034^{\mathrm{b}}$ \\
\hline
\end{tabular}

a Both patient acquisitions were compared with both control acquisitions.

b Significant.

son, only 16 (of 20) patients had the corresponding MR imaging acquisitions; therefore, these analyses were made considering this reduced group (16 patients). In addition, GLCM parameters that were found significant were correlated to clinical variables (age, age at onset, disease duration, GAA1, GAA2, Friedreich Ataxia Rating Scale total score) within the patient group. A $t$ test comparing the age of the groups was also performed to ensure that ages were matched.

\section{RESULTS}

We will refer to P1 as the group corresponding to the first set of images (20 images) of the patients with FA, P2 as the group corresponding to the second set (16 images, obtained 1 year later) of the patients with FA, and C1 and C2 correspond to the first and second sets of control acquisitions, respectively (21 images each, obtained 1 year apart).

The FA and control groups were not significantly different regarding age $(t$ test; $P=.99$ for $\mathrm{P} 1 \times \mathrm{C} 1 ; P=.69$ for $\mathrm{P} 1 \times \mathrm{C} 2 ; P=$ .60 for $\mathrm{P} 2 \times \mathrm{C} 1 ; P=.86$ for $\mathrm{P} 2 \times \mathrm{C} 2)$.

Longitudinal comparison of GLCM texture parameters for images obtained 1 year apart did not show significant alterations for either the control group $(\mathrm{C} 1 \times \mathrm{C} 2, t$ test, $P>.05$ for all parameters $)$ or the FA group $(\mathrm{P} 1 \times \mathrm{P} 2, t$ test, $P>.05$ for all parameters) for the analyzed structures (medulla oblongata and pons).

For the transversal study, because there were no significant age differences between groups, both patient acquisitions were compared with both control acquisitions, to verify the reproducibility of the results. Significant changes between patients with FA and controls were found for many GLCM parameters for the medulla oblongata, for all comparisons $(\mathrm{P} 1 \times \mathrm{C} 1, \mathrm{P} 1 \times \mathrm{C} 2, \mathrm{P} 2 \times \mathrm{C} 1, \mathrm{P} 2 \times$ $\mathrm{C} 2)$; and only 1 parameter, for 1 comparison $(\mathrm{P} 2 \times \mathrm{C} 2)$, showed significant differences for the pons. These results are summarized in the Table. In this Table, only parameters that were significant for at least 1 comparison are shown. All remaining parameters were not significant, for any comparison.
There were no significant correlations between significant GLCM parameters and clinical variables.

\section{DISCUSSION}

The aim of the present work was to investigate brain stem damage in FA by using texture analysis of T1-weighted images. Indeed, texture analysis based in the GLCM is a technique capable of extracting a set of parameters that characterize the gray level distribution of the analyzed ROIs. In turn, the gray level distribution reflects physical properties of the underlying tissues, in this case related to the local proton attenuation and $\mathrm{T} 1$ constant of the tissue, because T1-weighted MR images were used. In addition, because the resolution of the images used was $1 \mathrm{~mm}^{3}$, the reflected tissue properties are an average of microscopic characteristics (see De Certaines et $\mathrm{al}^{26}$ for a discussion on the limitations of correlating texture analysis results to histology). Nevertheless, obtained results showed significant alterations for patients with FA compared with controls, mainly for the medulla oblongata. In particular, the results for the medulla were very robust because most of the significant parameters were robust for all the comparisons made between the different sets of images obtained from patients with FA and controls. Conversely, the result found for the pons, in which only 1 parameter was significant (difference variance) for only 1 of the comparisons $(\mathrm{P} 2 \times \mathrm{C} 2)$, may be regarded as a highly probable spurious finding. Most interesting, there were no alterations found in the longitudinal study. This could be because the time span (1 year) was too small for noticeable changes in such a slowly evolving disorder. In fact, in analyses of a large set of control images, no changes with age were found in texture parameters for the medulla oblongata or pons (unpublished data, T.A.S. and G.C., 2014).

We believe that the texture abnormalities found here reflect bulbar structural changes, but not exactly atrophy of the structure. This hypothesis is supported by a previous texture-based study in patients with a related neurodegenerative disorder, namely amyotrophic lateral sclerosis, that identified prominent 
texture abnormalities earlier than true volumetric reduction. ${ }^{27}$ Also in line with these findings, some previous volumetric studies in FA failed to identify bulbar atrophy, ${ }^{17}$ and others actually found it, ${ }^{15}$ but it was restricted to the dorsal part of the structure in such a way that it would be difficult to explain our consistent texture modifications. Therefore, we opted not to include volumetric measurements of the medulla as a covariate in our statistical approach to compare groups.

The GLCM parameters that were significant for the medulla oblongata can be roughly divided into 3 groups, according to "the purpose of the weights in the corresponding equations." 28 These groups can help chart a slightly more intuitive meaning of the findings.

One group is related to descriptive statistical measures of the $\mathrm{GLCM}^{28}$ and includes the parameters correlation, variance, sum average, and sum variance. In particular, the correlation parameter, which gives a measure of the linear dependency between the gray levels of co-occurring (separated by the given distance) pixels, was consistently significant for the medulla oblongata for all GLCM distances for all comparisons, with the only exception being distance 5 for $\mathrm{P} 1 \times \mathrm{C} 2$, though in this case, the $P$ value was very close to significance $(P=.055$, Table). It has already been shown that this measure has the same expectation as the autocorrelation coefficient, particularly when the distance between pixels used in the GLCM calculation is small compared with the ROI dimensions, ${ }^{29}$ which was the case here for the smallest GLCM distances ( 1 and 2 pixels) (Appendix). The correlation was smaller for patients compared with controls, for all distances; this difference therefore indicates a decrease in the autocorrelation coefficient for the gray level distribution of the medulla oblongata for the patients with FA. In other words, the gray level distribution of this ROI is less stationary or less periodic for patients than for controls.

The variance parameter measures the dispersion of the gray level distribution; the sum average and sum variance parameters measure, respectively, the mean and the dispersion of the distribution related to the sum of the co-occurring gray levels (On-line Table). From these 3 parameters, only the sum average was significant for all comparisons (Table), with variance and sum variance only significant for the comparison $\mathrm{P} 1 \times \mathrm{C} 1$. All these parameters were smaller for patients with FA compared with controls. This finding therefore indicates a smaller mean and perhaps a tendency to a decrease in dispersion of the co-occurring gray level values for the medulla oblongata of patients with FA.

In another group are the entropy measures (entropy, sum entropy, and difference entropy). Entropy is a widely known measure coming from information theory, ${ }^{30}$ which can be used to evaluate the amount of orderliness or the information content of a dataset. The greater the entropy, the more random is the underlying distribution (in this case, the distribution of the co-occurring gray levels or the distribution of the sum of the co-occurring gray levels or the distribution of the difference of the co-occurring gray levels). In the present analysis, all these measures were decreased for patients with FA compared with controls. In terms of the gray level distributions (both the original between co-occurring pixels and the sum and difference distributions), the decrease of the entropy measures points to the appearance of some sort of orderliness in the data of patients with FA for the medulla oblongata, which was not there in the control data.

Finally, in the last group, related to contrast measures, which "use weights related to the distance from the GLCM diagonal," 28 is homogeneity, which, as shown by its name, is related to the homogeneity of the ROI. This parameter was significant for 3 of the comparisons (the only exception being $\mathrm{P} 1 \times \mathrm{C} 2$, Table), and it decreased for patients with FA compared with controls.

Together, these results indicate probable changes in the underlying tissue composing the medulla oblongata. Although, to the best of our knowledge, there are no studies correlating in vivo texture measures with histopathology, Zhang et $\mathrm{al}^{31}$ performed a study in which they found correlation among histopathology and texture parameters obtained from MR imaging of postmortem tissue samples of patients with multiple sclerosis. Possible tissue changes in the medulla oblongata are in line with previous pathologic reports in FA. In fact, medullar atrophy has been described since the original descriptions of Nikolaus Friedreich. ${ }^{32}$ This atrophy is mostly due to neuronal loss and shrinkage of gracile and cuneate nuclei, which are related to the dorsal sensory pathways in the spinal cord. In addition, corticospinal tracts are also damaged at this point. ${ }^{14}$ The lack of correlation between texture parameters and clinical data was somewhat unexpected but might be related to our segmentation strategy. We opted to use large ROIs that included the whole medulla oblongata, and neurodegeneration in FA is not homogeneous in this region (posterior structures are more severely damaged). Future studies using smaller ROIs within the medulla might prove useful in this setting.

\section{CONCLUSIONS}

In the present work, we found statistically significant differences for the medulla oblongata of patients with Friedreich ataxia compared with healthy individuals, by using GLCM-based texture analysis. These results highlight the medulla as an important site of damage in FA.

\section{APPENDIX}

ROI dimensions decrease with GLCM distance. In this work, the mean ROI areas used ranged approximately from 110 pixels (for a distance of 5 pixels) to 240 pixels (for a distance of 1 pixel) for the medulla of the patients with FA; from 160 to 300 pixels for the medulla of the controls; from 380 to 570 pixels for the pons of the patients with FA; and from 320 to 500 pixels for the pons of the controls. The area distributions were not significantly different between groups for any of the ROIs.

Disclosures: Thallis A. Santos—RELATED: Grant: São Paulo Research Foundation (undergraduate student). Márcia S. Oliveira-UNRELATED: Grants/Grants Pending: São Paulo Research Foundation. Marcondes C. França, Jr—RELATED: Grant: São Paulo Research Foundation grant 13/01766-7, * Comments: The São Paulo Research Foundation is a governmental agency that supports research in Brazil. Gabriela Castellano—RELATED: Other: São Paulo Research Foundation, ${ }^{*}$ Comments: São Paulo Research Foundation has provided financial support for purchasing most of the equipment used in this study, such as computers and, especially, the MRI scanner. *Money paid to the institution.

AJNR Am J Neuroradiol 36:2214-18 Dec 2015 www.ajnr.org 


\section{REFERENCES}

1. Hajek M, Dezortova M, Materka A, et al. Texture Analysis for Magnetic Resonance Imaging. Prague: Med4Publishing; 2006

2. Bonilha L, Kobayashi E, Castellano G, et al. Texture analysis of hippocampal sclerosis. Epilepsia 2003;44:1546-50 CrossRef Medline

3. Coelho GR, Kobayashi E, Bonilha L, et al. Hippocampal texture analysis in patients with familial mesial temporal lobe epilepsy. Arq Neuropsiquiatr 2003;61(suppl 1):83-87 CrossRef Medline

4. de Oliveira MS, Betting LE, Mory SB, et al. Texture analysis of magnetic resonance images of patients with juvenile myoclonic epilepsy. Epilepsy Behav 2013;27:22-28 CrossRef Medline

5. de Oliveira MS, D'Abreu A, França Jr MC, et al. MRI-texture analysis of corpus callosum, thalamus, putamen, and caudate in Machado-Joseph disease. J Neuroimaging 2012;22:46-52 CrossRef Medline

6. Mahmound-Ghoneim D, Toussaint G, Constans JM, et al. Three dimensional texture analysis in MRI: a preliminary evaluation in gliomas. Magn Reson Imaging 2003;21:983-87 CrossRef Medline

7. Herlidou-Même S, Constans JM, Carsin B, et al. MRI texture analysis on texture test objects, normal brain and intracranial tumors. Magn Reson Imaging 2003;21:989-93 CrossRef Medline

8. Sasikala M, Kumaravel. A wavelet-based optimal texture feature set for classification of brain tumours. J Med Eng Technol 2008; 32:198 205 CrossRef Medline

9. Haralick R, Shanmungam K, Dinstein I. Textural features for image classification. IEEE Trans Syst Man Cybern 1973;3:610-12 CrossRef

10. Haralick R. Statistical and structural approaches to texture. Proc IEEE 1979;67:786-804 CrossRef

11. Pandolfo M. Friedreich ataxia. Arch Neurol 2008;65:1296-303 CrossRef Medline

12. Fogel BL, Perlman S. Clinical features and molecular genetics of autosomal recessive cerebellar ataxias. Lancet Neurol 2007;6:245-57 CrossRef Medline

13. Campuzano V, Montermini L, Moltò MD, et al. Friedreich's ataxia: autosomal recessive disease caused by an intronic GAA triplet repeat expansion. Science 1996;271:1423-27 CrossRef Medline

14. Koeppen AH, Mazurkiewicz JE. Friedreich ataxia: neuropathology revised. J Neuropathol Exp Neurol 2013;72:78-90 CrossRef Medline

15. Della Nave R, Ginestroni A, Giannelli M, et al. Brain structural damage in Friedreich's ataxia. J Neurol Neurosurg Psychiatry 2008;79: 82-85 CrossRef Medline

16. Della Nave R, Ginestroni A, Diciotti S, et al. Axial diffusivity is increased in the degenerating superior cerebellar peduncles of Friedreich's ataxia. Neuroradiology 2011;53:367-72 CrossRef Medline
17. França MC Jr, D’Abreu A, Yassuda CL, et al. A combined voxel-based morphometry and 1H-MRS study in patients with Friedreich's ataxia. J Neurol 2009;256:1114-20 CrossRef Medline

18. Silva CB, Yasuda CL, D'Abreu A, et al. Neuroanatomical correlates of depression in Friedreich's ataxia: a voxel-based morphometry study. Cerebellum 2013;12:429-36 CrossRef Medline

19. Chevis CF, da Silva CB, D'Abreu A, et al. Spinal cord atrophy correlates with disability in Friedreich's ataxia. Cerebellum 2013;12: 43-47 CrossRef Medline

20. Rizzo G, Tonon C, Valentino ML, et al. Brain diffusion-weighted imaging in Friedreich's ataxia. Mov Disord 2011;26:705-12 CrossRef Medline

21. Pagani E, Ginestroni A, Della Nave R, et al. Assessment of brain white matter bundle atrophy in patients with Friedreich ataxia. Radiology 2010;255:882-87 CrossRef Medline

22. Akhlaghi H, Corben L, Georgiou-Karistianis N, et al. Superior cerebellar peduncle atrophy in Friedreich's ataxia correlates with disease symptoms. Cerebellum 2011;10:81-87 CrossRef Medline

23. Subramony SH, May W, Lynch D, et al; Cooperative Ataxia Group. Measuring Friedreich ataxia: interrater reliability of a neurologic rating scale. Neurology 2005;64:1261-62 CrossRef Medline

24. Materka A, Strzelecki M. Texture analysis methods: a review. In: Proceedings of the Annual Meeting of COST B11: Technical University of Lodz, Poland, Brussels, Belgium. June 25-28, 1988

25. Materka A. MaZda User's Manual. Version 3.30. Lodz University of Technology; Institute of Electronics: 1998-2000. http://www.eletel. p.lodz.pl/programy/mazda/download/mazda_manual.pdf. Accessed August 13, 2015.

26. De Certaines JD, Larcher T, Duda D, et al. Application of texture analysis to muscle MRI: 1-what kind of information should be expected from texture analysis? EPJ Nonlinear Biomedical Physics 2015; 3:3 CrossRef

27. de Albuquerque M, Anjos LG, Maia Tavares de Andrade H, et al. MRI texture analysis reveals deep gray nuclei damage in amyotrophic lateral sclerosis. J Neuroimaging 2015 May 25. [Epub ahead of print]

28. The GLCM Tutorial Home Page. http://www.fp.ucalgary.ca/mhallbey/ tutorial.htm. Accessed March 29, 2015

29. van der Sanden JJ, Hoekman DH. Review of relationships between grey-tone co-occurrence, semivariance, and autocorrelation based image texture analysis approaches. Canadian Journal of Remote Sensing 2005;31:207-13 CrossRef

30. Shannon CE. A mathematical theory of communication. The Bell System Technical Journal 1948;27:379-423 CrossRef

31. Zhang Y, Moore GR, Laule C, et al. Pathological correlates of magnetic resonance imaging texture heterogeneity in multiple sclerosis. Ann Neurol 2013;74:91-99 CrossRef Medline

32. Friedreich N. Ueber Ataxie mit besonderer Berücksichtigung der hereditären Formen: Nachtrag. Virchows Arch Pathol Anat Physiol Klin Med 1877;70: 140-52 